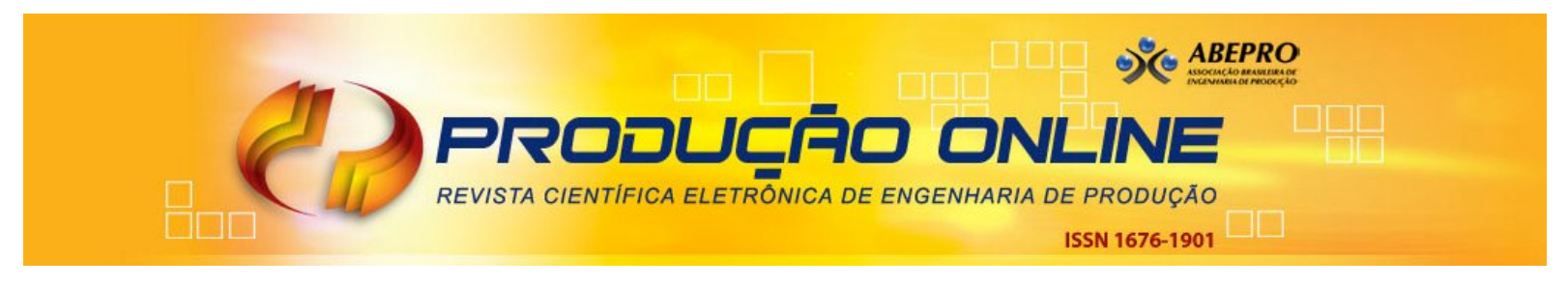

\title{
IDENTIFICAR E QUANTIFICAR OS METAIS PRESENTES DA LAMA DE ACIARIA E PROPOR UMA DESTINAÇÃO
}

\section{IDENTIFY AND QUANTIFY THE METALS PRESENT OF THE SLUDGE OF THE STEELWORKS AND PROPOSE A DESTINATION}

\author{
Alex Sibucks* E-mail: alex.sibucks@gmail.com \\ Charles Giovani de Oliveira* E-mail: charles.oliveira14@gmail.com \\ José Roberto Molica Filho* E-mail: robertomolica7@gmail.com \\ Janaina da Costa Pereira Torres de Oliveira* E-mail: janainacpto@gmail.com \\ Valmir Torres de Oliveira* E-mail: valmirtjt@gmail.com \\ *Centro Universitário Geraldo Di Biase (UGB), Volta Redonda, RJ
}

\begin{abstract}
Resumo: Atualmente a geração de resíduos industriais tem sido uma grande preocupação para sociedade e o meio-ambiente em que vivemos, por afetar diretamente as nossas vidas, seja por poluição, adequação às mudanças do ambiente, entre outras. Uma das indústrias que mais geram resíduos, atualmente, são as indústrias siderúrgicas que realizam vários processos para o aprimoramento e refino do metal bruto encontrado na natureza. A aciaria é a unidade de uma usina siderúrgica onde se gera uma grande quantidade de resíduos sólidos ou até mesmo líquidos que são de grande importância pela sua reutilização em diversos setores como na produção de cimentos, estradas entre outros. Dois importantes resíduos de aciaria são a escória e a lama. A identificação e quantificação dos metais presentes nos resíduos de aciarias é o primeiro passo para o entendimento de como esses resíduos podem ser manipulados e transformados em novos insumos industriais ou produtos comercializáveis, ajudando na redução de resíduos descartados e aumentando a eficiência da indústria. Este trabalho tem como objetivo identificar e quantificar os metais presentes na lama de aciaria, e propor sua destinação. Análises químicas e físicas foram realizadas em laboratório para identificar e quantificar a lama de aciaria, sendo que o metal presente com maior quantidade em massa foi o ferro, porém bem abaixo do esperado, limitando sua aplicação, portanto, foi proposto a utilização da lama como agregado miúdo na fabricação de lajotas e outros materiais cerâmicos.
\end{abstract}

Palavras-chaves: Siderurgia. Resíduo sólido. Lama de aciaria.

\begin{abstract}
Currently the generation of industrial waste has been a great concern for society and the environment in which we live, because it directly affects our lives, whether by pollution, adaptation to environmental changes, among others. One of the industries that generate the most waste today is the steel industry that performs several processes for the improvement and refining of the raw metal found in nature. The steelworks is the unit of a steel industry where a large amount of solid or even liquid wastes are generated which are of great importance for their reuse in various sectors such as the production of cements, roads and others. Two important waste of steelworks are slag and sludge. The identification and quantification of the metals present in steelworks waste is the first step in understanding how these wastes can be handled and transformed into new industrial inputs or marketable products, helping to reduce discarded waste and increasing the efficiency of the industry. This work aims to identify and quantify the metals present in the slurry of steelworks, and to propose its destination. Chemical and physical analyzes were carried out in the laboratory to identify and quantify the sludge of steelworks, and the metal present with the greatest mass was the iron, but well below the expected, limiting its application, therefore, it was proposed to use the sludge as aggregate in the manufacture of tiles and other ceramic materials.
\end{abstract}


Keywords: Steel industry. Solid waste. Sludge of steelworks.

\section{INTRODUÇÃO}

Com os recursos naturais e econômicos cada vez mais escassos na realidade contemporânea é imprescindível a reutilização e a criação de novas tecnologias para o reuso de certos resíduos, gerados por vários setores, sejam eles industriais, comerciais entre outros. Com a reutilização, as indústrias ou empresas conseguem lucrar com algo que seria posteriormente descartado, ou até mesmo traria algum custo para empresa, seja por danos ambientais, custeio de áreas apropriadas para alocação de descarte, entre outros. Um dos setores industriais que mais geram resíduos com um potencial significativo de reuso e criação de novos produtos e utilização é o meio siderúrgico, mais especificamente o processo da aciaria, que tem como principais resíduos, a escória e a lama.

A utilização da escória, atualmente, é bem diversificada podendo ser utilizada em diversos fins como na matéria prima de vidros e vitro-cerâmica, estabilização de solos por ter maior rugosidade superficial, na produção de fertilizantes agrícolas, na produção de cimentos devido à presença de silicatos dicálcico e tricálcico, em lastros ferroviários devido a grande massa específica, usado como agregados na produção de concretos e em estradas rodoviárias (Branco, 2004).

Entretanto, a lama de aciaria é rica em ferro, e segundo Ereno (2007, p. 69) "Os resíduos portadores de ferro são transformados em pequenas pelotas, tratados termicamente e reintroduzidos no processo produtivo, transformando-se em gusa novamente e depois em aço".

O estudo e a manipulação dos resíduos de aciaria com passar das décadas se torna mais significativo, por proporcionar um aumento no lucro das empresas e redução de impactos ambientais. Este trabalho tem como objetivo caracterizar os constituintes presentes na lama de aciaria, e propor sua destinação, com vista no aproveitamento os mesmos. 


\section{REFERENCIAL TEÓRICO}

\subsection{Aciaria}

A produção de aço é realizada, sobretudo a partir de minério de ferro, carvão e cal. O aço é produzido em quatro etapas: preparação da carga, redução, refino e laminação. O setor de refino mais conhecido é denominado de aciaria. O refino é feito em fornos especiais, denominados conversores a oxigênio, dos quais o mais utilizado é o chamado conversor LD (Linz e Donawitz). A aciaria é o equipamento responsável pela fabricação do aço em uma usina siderúrgica após a produção do ferro gusa no alto forno, ou do ferro esponja na redução direta, que envolve basicamente a oxidação de grande parte do carbono, reduzido de níveis acima de 4\% para inferiores a 1\% na maioria dos casos e, de impurezas como fósforo, enxofre e outras, que são eliminadas na escória, enquanto o excesso de carbono é eliminado sob a forma de gás, CO e $\mathrm{CO}_{2}$. Depois da obtenção do aço líquido, o mesmo é solidificado em equipamentos de lingotamento contínuo para a produção de semi-acabados, lingotes e blocos. De acordo com o Centro de Gestão e Estudos Estratégicos (CGEE):

\footnotetext{
As duas principais rotas tecnológicas siderúrgicas são: a) Usinas integradas a coque, que usam alto-forno para a produção de ferro-gusa, que depois é transformado em aço nos conversores básicos a oxigênio; b) As usinas semiintegradas (minimills), cuja fase inicial de produção é a aciaria elétrica. (CGEE, 2010, p. 51)
}

\subsubsection{Aciaria LD}

A transformação do ferro-gusa em aço é feita em conversores a oxigênio, por meio da oxidação dos elementos do gusa que precisam ser retirados ou diminuídos, como o carbono, silício, fósforo, enxofre e outros, conforme mostrado na Figura 1.

Figura 1 - Operação do conversor LD. 

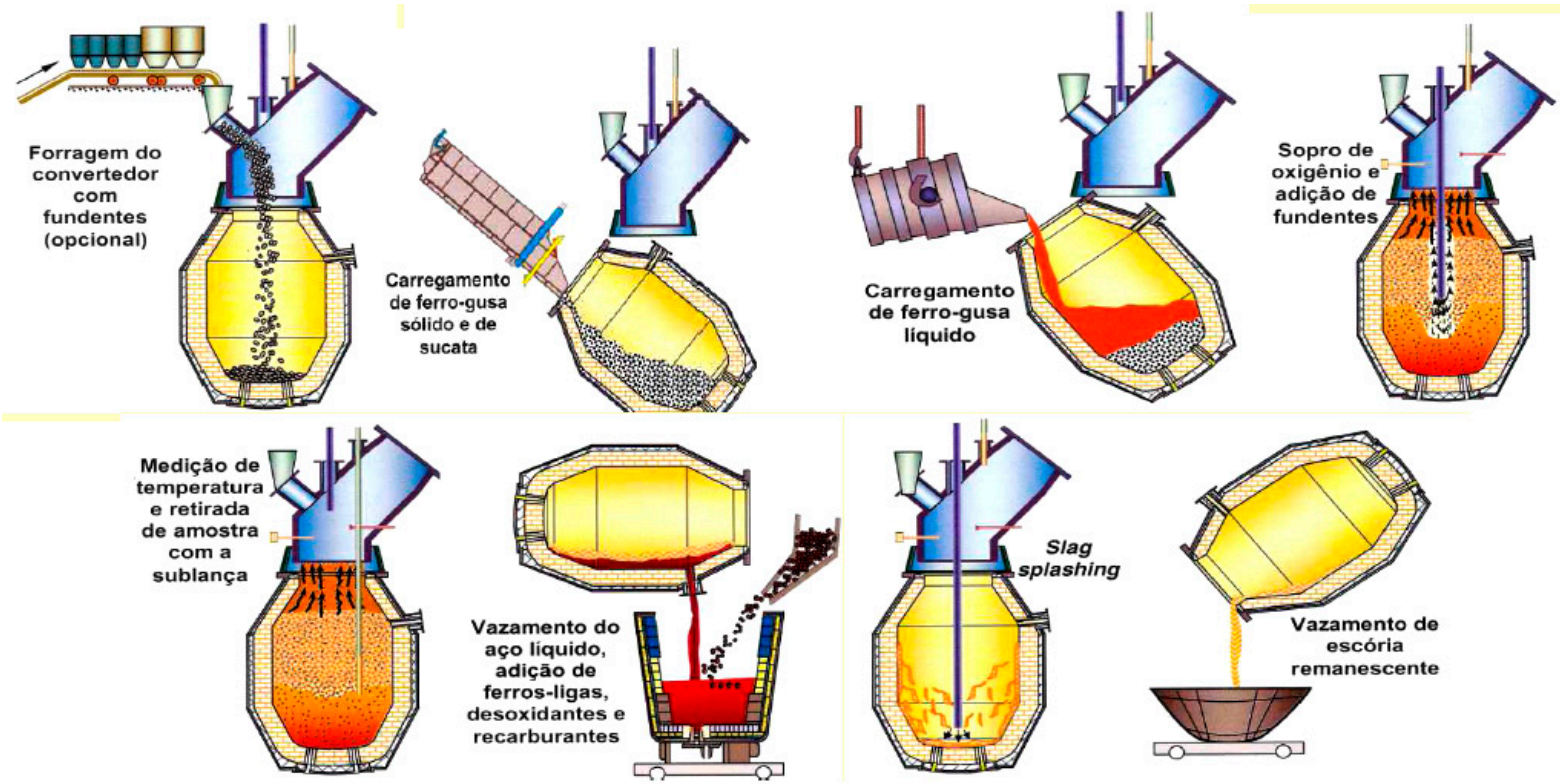

Fonte: SILVA (2013, p. 45).

A taxa destes elementos, no gusa, faz com que esse metal, muitíssimo frágil, fique impossibilitado, em sua grande maioria, de ser utilizado como material de engenharia, por isso, se faz necessário a redução destas taxas nos conversores LD. A empregabilidade de sucata de aço nos conversores impede que a temperatura alcance taxas muito altas no decurso da oxidação. O aço líquido é conduzido em panela até o lingotamento contínuo.

Podem ser mencionados como fundamentais benefícios do processo LD, a rapidez na modificação do gusa líquido em aço e o reaproveitamento da sucata de recirculação interna.

A utilização do oxigênio já havia sido sugerida por Bessemer muitos anos antes da primeira produção de aço por sopro de oxigênio, porém devido elevado custo de separação do oxigênio do ar, isso só foi possível apenas durante a segunda Guerra, onde o preço do oxigênio tornou-se disponível a preços suficientes baixos. (TOLEDO JUNIOR, 2015, p. 9)

Conforme CGEE no contexto internacional:

O conversor básico a oxigênio é o tipo de aciaria mais utilizada na siderurgia mundial. Esta tecnologia foi originalmente desenvolvida em meados do século passado pela siderúrgica austríaca Vöest-Alpine. Pelo fato de ter sido empregada inicialmente nas usinas Linz e Donawitz, ela ficou também conhecida como aciaria LD. (CGEE, 2010, p. 51) 
Já no contexto brasileiro, a siderurgia mostra uma maior taxa de difusão da aciaria LD diante à siderurgia mundial, como reflexo da acessibilidade de minério de ferro de altíssimo padrão.

A parte dos desafios da siderurgia no Brasil no que diz respeito à aciaria LD é equivalente aos enfrentados pelos similares internacionais (CGEE, 2010). Portanto, na aciaria LD a CGEE (2010) recomenda, no que diz respeito ao aprimoramento do desempenho ambiental, a elaboração de pesquisas sobre a combustão e póscombustão dos gases do processo; desenvolvimento de pesquisas para que se aproveitem as escórias e lamas de aciaria tendo como objetivo a redução da amplificação das escórias, tipo da cal livre; etc.

\subsection{Resíduos de aciaria LD}

Conforme a CGEE (2010), dois resíduos sólidos são produzidos na fase de refino primário do aço empregando-se convertedores LD: escórias e lamas. É possível dizer que a escória não tem aplicação comercial relevante, ainda que seja viável usála como contrapeso em linha férrea ou autoestradas e corretivo de solos, entre outras empregabilidades. Já a lama de aciaria, que é composta pelo pó retirado a úmido no sistema de filtragem de gases, mostra um obstáculo na reciclagem.

\subsubsection{Escória}

As escórias são geradas em certas fases do processo siderúrgico, no alto forno, na aciaria LD, aciaria elétrica e na metalurgia secundária. Em virtude da utilização de altas temperaturas nos diversos processos, as escórias não possuem matérias orgânicas.

De acordo com Diniz e Oliveira (2009, p. 290) um dos fatores mais importantes para geração da escoria é basicamente a composição química do metal, porém depende de outros fatores como temperatura e tempo de fusão do material, utilizado no processo de transformação do mesmo.

A escória de aciaria é desse modo, um resíduo da produção do aço e é gerada durante o processo de refino do gusa dentro dos fornos de preparação do aço; a 
escória ocorre como um líquido fundido e tem composição química complexa de silicatos e óxidos que se solidificam posteriormente ao resfriamento.

Desse modo, a escória de aciaria é gerada como resultado de um processo controladíssimo, tendo como intuito a sua obtenção apropriada ao mercado de consumo. Mundialmente, a produção atual é praticamente realizada em usinas integradas que utilizam o processo a sopro de oxigênio LD e usinas semi-integradas, que utilizam os Fornos Elétricos a Arco (FEAs). E no término do processo de refino, o aço líquido é vazado para uma panela, enquanto que a escória é retida no vaso do convertedor e posteriormente vazado para um pote de escória.

\begin{abstract}
Escórias siderúrgicas são produtos resultantes de processos industriais destinados a obter, em primeiro lugar, o gusa, e em segundo lugar, o aço. A escória de aciaria é gerada no processo de fabricação do aço, resultante da transformação do ferro gusa líquido em aço. A sigla LD deve-se ao fato do aço ser produzido no conversor de oxigênio tipo LD (Linz-Donawitz). A escória líquida ao ser retirada do conversor, com temperatura da ordem de $1400^{\circ} \mathrm{C}$ é transportada para um pátio, denominado pátio de escória, onde são basculadas em baias previamente preparadas. (ARCELOR MITTAL BRASIL, 2015 , p. 1)
\end{abstract}

De acordo com Dildin e Chumanov (2009) foram feitas pesquisas experimentais com altas temperaturas $\left(1000-1500^{\circ} \mathrm{C}\right)$ para extração de metais da escória, as análises foram dividas basicamente em duas etapas que são redução da fase sólida e redução da fase líquida (fusão). Resultados metalográficos demonstram que cerca de $80 \%$ dos materiais metálicos contidos na amostra da escória utilizado no processo termodinâmico foi perdido pela alta redução do material em sua fase física. Com isso, é possível observar que mesmo com um processo muito eficaz na extração de materiais metálicos da escória, sempre haverá uma grande redução do material, porém compensado pelo baixo custo da obtenção desse material, por ser um resíduo.

A Figura 2 mostra o fluxo de geração e tratamento da escória produzida em uma aciaria LD.

Figura 2 - Fluxo de geração e tratamento da escória de aciaria LD

Revista Produção Online. Florianópolis, SC, v. 19, n. 1, p. 274-289, 2019. 


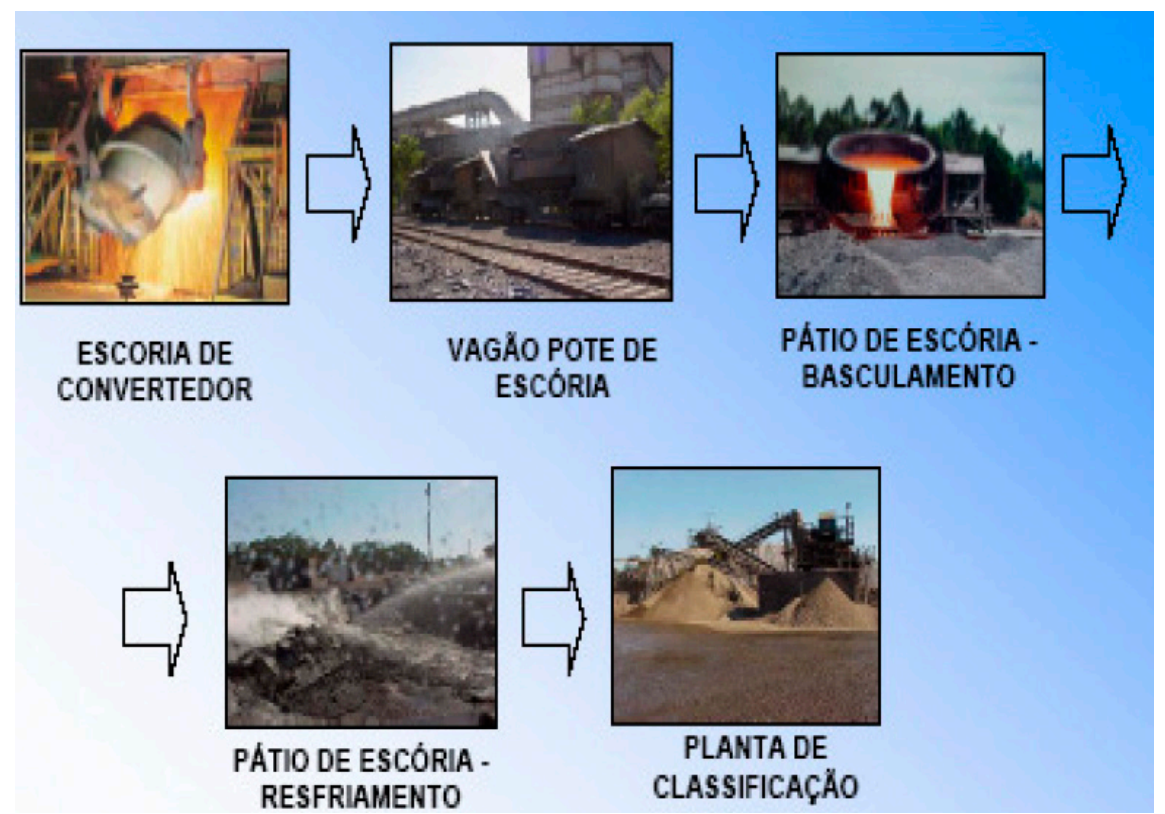

Fonte: Souza (2007, p. 19)

No tratamento das escórias da aciaria, as empresas precisam procurar auxílio das organizações ambientais para que possam adotar políticas e mecanismos que estimulem a reciclagem de materiais, tendo como base a definição de eco eficiência. Além disso, é necessário projetar testes e ensaios para a realidade brasileira, do funcionamento das escórias de aciaria na edificação de rodovias. Incentivar a empregabilidade mais intensiva da escória de aciaria, fundamentada nos benefícios ambientais resultantes, diversificando mercados e inserindo mais valor à escória.

\subsubsection{Lama}

As lamas são resultantes do sistema de tratamento a úmido dos gases que são gerados e liberados no processo siderúrgico. Em virtude à quantidade de partículas inclusa nos gases dos processos siderúrgicos, a higienização das correntes gasosas resulta na formação de um resíduo sólido, ou seja, a lama. Contrariamente às escórias, as lamas se mostram com uma dificuldade mais complexa, devido a grande variedade de características físicas e químicas e a existência de componentes indesejados, por esta razão a reciclagem da lama de aciaria LD necessita de um estudo mais aprofundado.

Nas lamas de aciaria LD o gerenciamento não se encontra tão avançado quanto o da escória LD. Como a lama gerada no processo LD possui um Revista Produção Online. Florianópolis, SC, v. 19, n. 1, p. 274-289, 2019. 
grande teor de ferro (40-70\% de FeO), a tendência é que ela seja reciclada por sinterização na própria siderúrgica. O zinco presente provido da sucata galvanizada tem sido um problema. Desta forma, o desenvolvimento de processos pirometalúrgicos, hidrometalúrgicos e híbridos se fazem inevitável. (RONDA FILHO, 2016, p. 33)

A Figura 3 mostra o fluxograma de tratamento da lama produzida em uma aciaria LD.

Figura 3 - Fluxograma de tratamento da lama de aciaria LD.

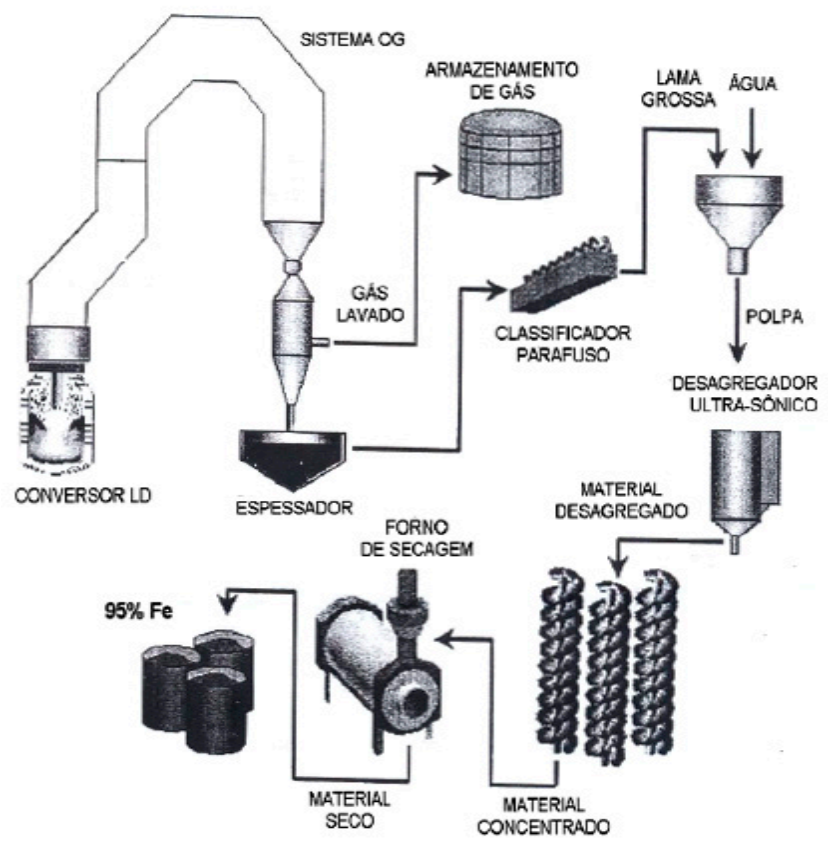

Fonte: SOUZA, et al. (2002)

As lamas de aciaria são resíduos mais ricos em ferro e, deste modo necessitam ser tratadas com muita prudência, objetivando um processo de reciclagem de tais rejeitos sólidos, em uma usina integrada.

Conforme Ereno (2007), a CSN (Companhia Siderúrgica nacional) adotou desde fevereiro de 2007, em escala industrial, um processo que permite reaproveitar o ferro contido na lama gerada no alto-forno e na aciaria, nos processos de redução e refino do aço, resultando em ganhos econômicos e ambientais para a empresa. Por volta de 80 mil toneladas de lama, das 120 mil toneladas produzidas ao ano, na CSN, são recuperadas. Contudo para que isso aconteça, o resíduo que possui em sua composição 30\% de óxido de ferro e $70 \%$ de carbono e argila, passa por um processo para a separação do resíduo metálico. 
Ereno (2007, p. 69) diz que "Os resíduos portadores de ferro são transformados em pequenas pelotas, tratados termicamente e reintroduzidos no processo produtivo, transformando-se em gusa novamente e depois em aço".

\section{MATERIAIS E MÉTODOS}

\subsection{Materiais}

Os equipamentos utilizados na caracterização da lama de aciaria LD são descritos a seguir:

\subsubsection{Estufa microprocessada de secagem}

Tem em sua característica uma estrutura externa de aço revestida com epóxi eletrostático, geralmente no formato cúbico, contém uma ou até duas portas, temperatura de utilização entre 15 e $300^{\circ} \mathrm{C}$, contém um termostato para o controle de energia caso ocorra queda de energia ou erro no sistema. Utilizada na remoção de umidade de resíduos sólidos e líquidos (NASCIMENTO, 2012). A Figura 4 mostra a foto da estufa microprocessada de secagem utilizada neste trabalho.

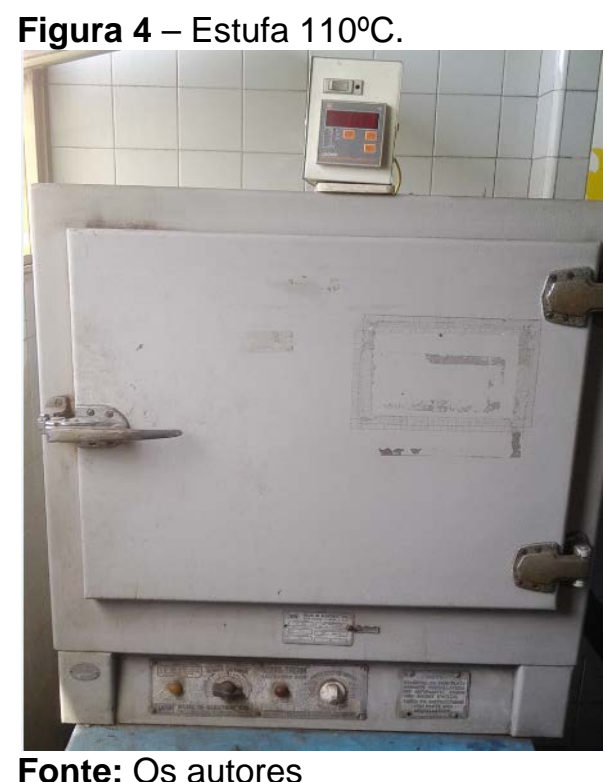

Revista Produção Online. Florianópolis, SC, v. 19, n. 1, p. 274-289, 2019. 


\subsubsection{Mufla}

Basicamente é um forno consistente formado por uma câmara metálica sendo revestida internamente por material refratário e uma resistência interna de mais de $1000^{\circ} \mathrm{C}$. Este tipo de forno possui câmaras para o aquecimento e combustão separados, ou seja, cinzas, gases e resíduos provenientes da combustão não contaminam as amostras. Este tipo de forno é utilizado em diversas análises que precisam de um superaquecimento do material sem a interferência dos resíduos gerados pela combustão (PROLAB, 2014). A Figura 5 mostra a foto da mufla de fusão utilizada neste trabalho.

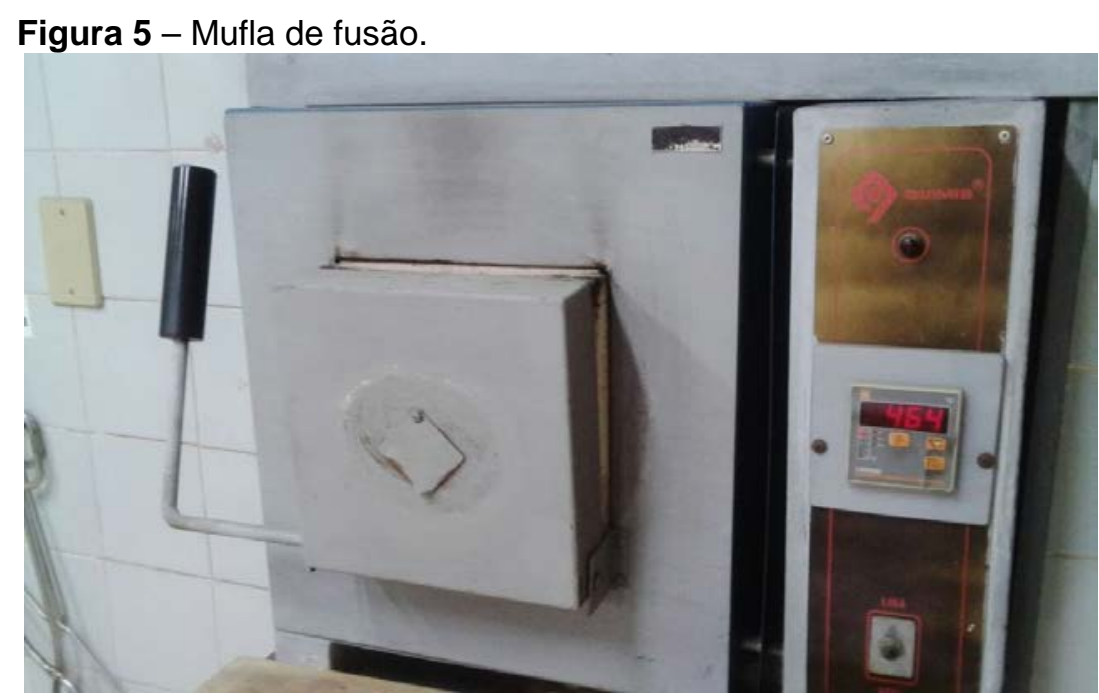

Fonte: Os autores

Na mufla ocorre o processo de calcinação que de acordo com Callister (2008) é o processo ou tratamento de remoção da água, dióxido de carbono e de outros gases ligados em uma substância geralmente hidratos e carbonatos. A calcinação é um processo fortemente endotérmico e é usada principalmente na produção de óxidos. Uma característica da calcinação é o uso de uma fase gasosa para transferir o calor necessário e, ao mesmo tempo, retirar os produtos gasosos da decomposição.

\subsubsection{Espectrômetro de plasma acoplado indutivamente (ICP)}

Revista Produção Online. Florianópolis, SC, v. 19, n. 1, p. 274-289, 2019. 
A espectrometria de plasma acoplado indutivamente é um processo que tem como vantagem a análise rápida de múltiplos elementos de um resíduo, para realizar esse processo é utilizado uma máquina com uma fonte de ionização de um plasma argônico (elemento químico de número atômico 18 da família dos gases nobres) de energia alta, possui também um detector espectrômetro de alta ou baixa resolução. Utilizando o ICP é possível detectar 90\% dos elementos da tabela periódica de um resíduo (WANDEKOKEN, 2016). A Figura 6 mostra a foto do ICP utilizado neste trabalho.

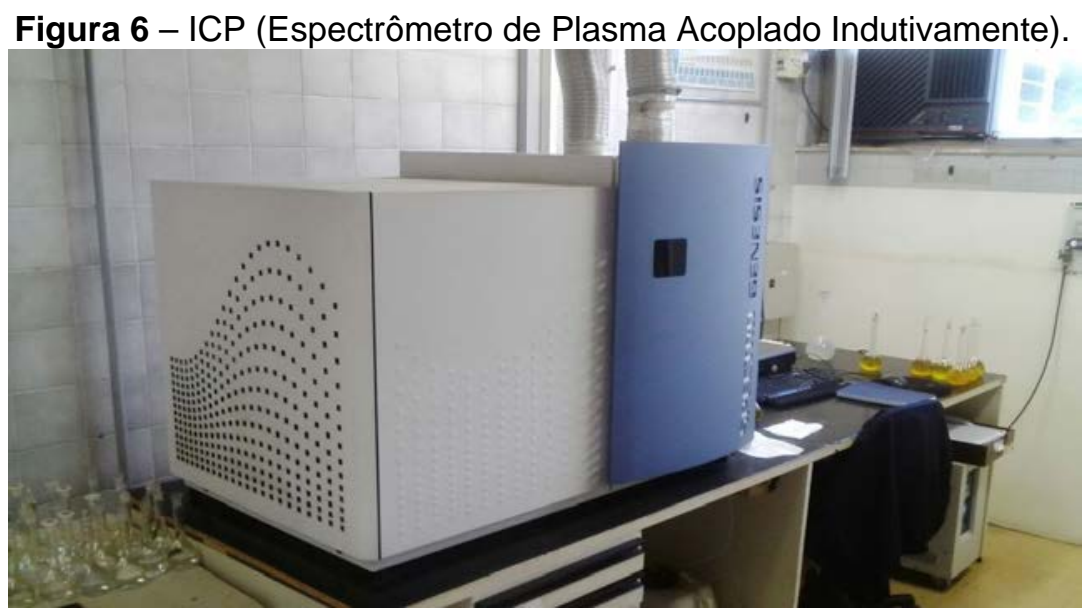

Fontes: Os autores

\subsection{Métodos}

O método de pesquisa utilizado neste trabalho foi quantitativo e experimental (APPOLINÁRIO, 2016, p. 40). Foram coletadas quatro amostras, de $10 \mathrm{~kg}$ cada, da lama recuperada de Aciaria LD em uma empresa siderúrgica da região. As amostras foram coletadas no pátio de armazenagem de resíduos de lama de aciaria, a amostragem foi realizada em diferentes pontos, para obtenção de uma maior representatividade, utilizando com base a norma brasileira de amostragem de resíduos sólidos (ABNT, 2004). A lama de aciaria LD utilizada já tinha sofrido uma etapa de recuperação, por isso, foi denominada de lama recuperada.

Após a realização da coleta as amostras foram encaminhadas para o Laboratório Químico e Físico para a realização dos ensaios necessários. Para 
caracterizar a lama, a primeira etapa foi retirar a umidade das amostras, isto é, as amostras foram levadas à estufa (Figura 4) em uma temperatura de $110^{\circ} \mathrm{C}$.

Para a realização da análise química as amostras passaram pelo processo de maceração, isto é, as amostras coletadas foram trituradas em gral de porcelana ( Figura 7) até uma granulometria inferior a 118mm (14mesh). A maceração é necessária para que, durante a análise química, a solubilização da amostra em meio aquoso ocorra de forma mais rápida.

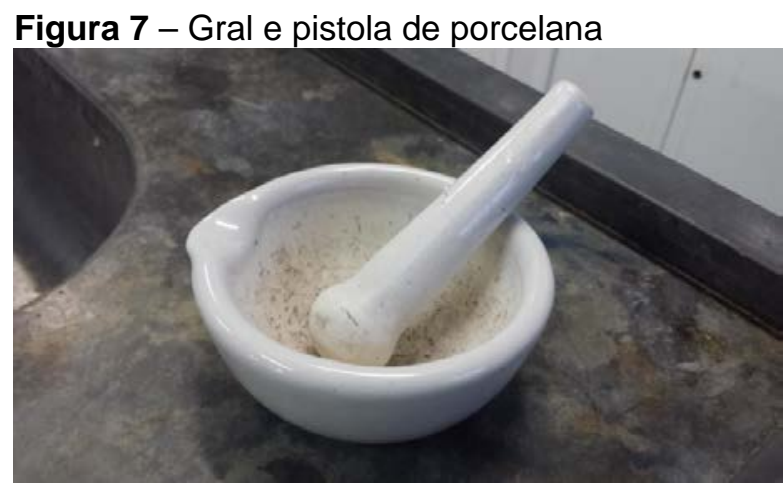

Fonte: Os autores

Após a maceração foi retirada uma parcela da amostra para o cadinho de platina e a seguir foi adicionada à mistura, fundente, para baixar o ponto de fusão do material, essa mistura foi levada à mufla de fusão (Figura 5) em temperatura de $950^{\circ} \mathrm{C}$ por 20 minutos.

Logo após a fusão, esse fundido foi levado a uma solução ácida composta por água e ácido clorídrico, com o objetivo de dissolver toda amostra. Esses balões volumétricos foram encaminhados para análise dos metais, através da técnica de espectrometria de plasma acoplado indutivamente no ICP (Figura 6).

A caracterização do ferro metálico, óxido de ferro e do ferro total se deu pelo processo titulométrico (Figura 8), que consiste na determinação da concentração de uma solução a partir de uma solução conhecida. 
Figura 8 - Titulação do ferro

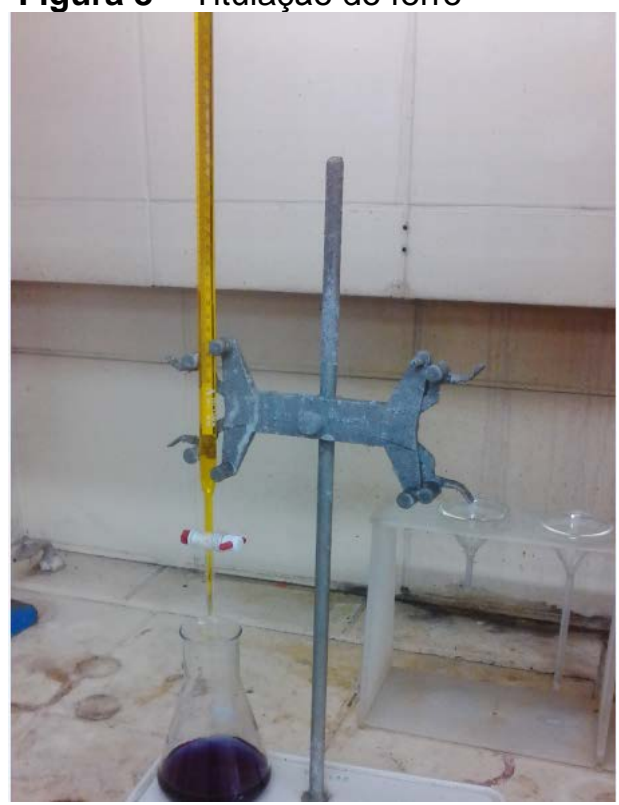

Fonte: Os autores

\section{RESULTADOS E DISCUSSÃO}

Na Tabela 1 foi registrada a porcentagem de umidade de cada amostra. A porcentagem de umidade é bastante significativa nas amostras pois a lama foi gerada em sistemas de tratamentos a úmido dos gases no processo de refino do aço. Porém para se extrair os elementos foi retirada a umidade presente nas amostras por meio da estufa (Figura 4).

Tabela 1 - Teor de umidade na lama de aciaria.

\begin{tabular}{cc}
\hline Lama de Aciaria & Umidade (\%) \\
\hline Amostras 1, 2 e 3 & 17,77 \\
Amostras 4a, 4b e 4c & 31,80 \\
\hline
\end{tabular}

Fonte: Os autores

Depois da estufa as amostras foram levadas a mufla (Figura 5), na mufla ocorreu o processo de calcinação, em ambiente não controlado e em ambiente controlado com nitrogênio, os resultados do processo de perda por calcinação estão representados na Tabela 2 .

Revista Produção Online. Florianópolis, SC, v. 19, n. 1, p. 274-289, 2019. 
Tabela 2 - Perda por calcinação - PPC

\begin{tabular}{cc}
\hline Lama de Aciaria (todas as amostras) & PPC (\%) \\
\hline Ambiente não controlado & -4 \\
Ambiente controlado com nitrogênio & 1
\end{tabular}

Fonte: Os autores

Como demonstrado na Tabela 2, as amostras que passaram pela mufla em ambiente não controlado tiveram um ganho de massa de $4 \%$ devido a sua oxidação e em ambiente controlado com nitrogênio, a perda foi de 1\%, de sua massa total.

Já Tabela 3 mostra a composição química dos elementos químicos presentes na lama de aciaria LD. Esta tabela atende a primeira etapa do trabalho que era de identificar e quantificar a lama de aciaria LD.

Tabela 3 - Composição química da lama de aciaria obtida pela técnica de espectroscopia de plasma acoplado indutivamente

\begin{tabular}{cccccccccc}
\hline $\begin{array}{c}\text { Lama de } \\
\text { Aciaria }\end{array}$ & \% Al & \% Cd & $\% \mathrm{Cr}$ & $\% \mathrm{Cu}$ & $\% \mathrm{Fe}_{\text {total }}$ & $\% \mathrm{Fe}^{\circ}$ & $\% \mathrm{Mn}$ & $\% \mathrm{Ni}$ & $\% \mathrm{Zn}$ \\
\hline Amostra 1 & 0,160 & 0,040 & 0,650 & 0,021 & 46,35 & 7,11 & 0,690 & 0,025 & 2,16 \\
Amostra 2 & 0,110 & 0,080 & 0,020 & 0,020 & 38,13 & 5,15 & 0,507 & 0,005 & 2,19 \\
Amostra 3 & 0,090 & 0,080 & 0,020 & 0,020 & 33,83 & 4,98 & 0,471 & 0,005 & 1,80 \\
Amostra 4a & 0,139 & 0,123 & 0,093 & 0,008 & 58,08 & 14,93 & 0,840 & 0,011 & 4,15 \\
Amostra 4b & 0,093 & 0,123 & 0,133 & 0,006 & 56,40 & 10,55 & 0,854 & 0,013 & 4,44 \\
Amostra 4c & 0,170 & 0,124 & 0,160 & 0,012 & 54,73 & 14,33 & 0,793 & 0,012 & 4,30 \\
\hline
\end{tabular}

Fonte: Os autores

Analisando a Tabela 3 foi possível observar que todos os elementos possuíam aproximadamente a mesma porcentagem, apenas o ferro metálico apresentou variação significativa, essa variação é devido a amostra ter sido retirada de locais distintos. O ferro total foi o que apresentou maior percentual, desde 33,83\% (amostra 3) a 58,08\% (amostra 4a), ele é o elemento mais importante para o objetivo deste trabalho. Como as amostras que foram coletadas já tinham sido reutilizadas pela empresa, a porcentagem de ferro metálico ficou empobrecida, com uma média de 9,5\% de ferro para cada amostra.

A segunda etapa do trabalho foi propor uma destinação comercial para a lama recuperada, portanto por apresentar uma quantidade de ferro metálico inferior ao esperado, uma proposta viável é utilizar a lama recuperada na fabricação de lajotas e 
outros materiais cerâmicos, devido a quantidade de ferro contida nas amostras ser insuficiente para outros fins como lastros de ferrovias, entre outros.

\section{CONSIDERAÇÕES FINAIS}

O desenvolvimento do trabalho permitiu extrair as seguintes conclusões: a primeira é que este trabalhou atendeu a um dos objetivos propostos que foi de caracterizar a lama de aciaria LD; a segunda é que após identificar a predominância de ferro metálico na lama, porém em quantidade inferior ao esperado, foi possível propor a utilização desse resíduo em produção de tijolos e materiais cerâmicos, associando-o a argila.

Sugestões para trabalhos futuros seria a de utilizar este resíduo na produção de tijolos ecológicos e verificar se os mesmos atendem as exigências de qualidade para essa modalidade de tijolos que não requerem queima em fornos.

\section{REFERÊNCIAS}

ABNT - ASSOCIAÇÃO BRASILEIRA DE NORMAS TÉCNICAS. Amostragem de Resíduos: NBR 10007:2004. Disponível em:

https://sites.unicentro.br/wp/educacaoambiental/files/2017/04/NBR-10007.pdf. Acesso em: 10 jun. 2017.

APPOLINÁRIO, F. Metodologia científica. 1. ed. São Paulo, SP: Cengage, 2016.

ARCELOR MITTAL BRASIL. Escória de aciaria LD. 2015. Disponível em: http://tubarao.arcelormittal.com/produtos/co produtos/catalogo produtos/escoria aciaria ld/i ntroducao.asp. Acesso em: 31 out. 2017.

BRANCO, V. T. F. C. B. Caracterização de Misturas Asfálticas com o uso de Escória de Aciaria como Agregado. Disponível em: http://wwwp.coc.ufri.br/ teses/mestrado/geotecnia/2004/Teses/BRANCO VTFC $04 \mathrm{t}$ M geo.pdf . Acesso em: 15 jul. 2017.

CALLISTER Jr, W. D. Ciência e engenharia de materiais: uma introdução. Rio de Janeiro, LTC, 2008.

CGEE, Centro de Gestão e Estudos Estratégicos. Siderurgia no Brasil: 2010-2025. Brasília, 2010.

DILDIN, A. N.; CHUMANOV, I. V. Study of the Processes of Metal Recovery from Steel Slags. Indian Journal of Science and Technology, v. 8, n. 34, p. 1-7, 2015. https://doi.org/10.17485/ijst/2015/v8i34/85338 
DINIZ, A. G. F.; OLIVEIRA, I. L. Influência das fontes de alumínio secundário na geração de escória: uma análise estatística. Revista Produção online, v. 9, n. 2, p. 284-302, 2009. https://doi.org/10.14488/1676-1901.v9i2.271

ERENO, D. Resíduo vira aço. Lama recuperada retorna ao processo produtivo na CSN. Pesquisa FAPESP. ed. 134. Abril de 2007. Disponível em:

http://revistapesquisa.fapesp.br/2007/04/01/residuo-vira-aco/. Acesso em: 14 nov. 2017.

NASCIMENTO, O. N.. Manual de instruções q317m estufa microprocessada de secagem com timer. QUIMIS: São Paulo, 2012.

PROLAB. Saiba o que é e como funciona um forno mufla, 2014. Disponível em: http://www.prolab.com.br/blog/saiba-o-que-e-e-como-funciona-um-forno-muflal. Acesso em: 13 dez. 2017.

RONDA FILHO, W. M. M. Levantamento dos resíduos sólidos gerados no refino primário (aciaria LD) de ferro gusa. Rio de Janeiro: UFRJ/Escola Politécnica, 2016.

SILVA, A. J. Estudos dos principais processos metalúrgicos de aciaria (EOF, FEA, LD). Divinópolis: Faculdade Pitágoras / Unidade Divinópolis, 2013. 54 p.

SOUZA, E. L.; ARAÚJO, F. G. S.; TENORIO, J. A. S.; GOMES, J. E. L.; OLIVEIRA, C. P. Tratamento de lamas siderúrgicas com o objetivo de recuperar seu teor metálico. In: CONGRESSO ANUAL DA ABM, 57., 2002. Anais... São Paulo, 2002.

SOUZA, E. B. de O. Escórias de aciaria e resíduos de concretos refratários em componentes de pavimentação. Belo Horizonte, UFMG, 2007. Disponível em: http://www.smarh.eng.ufmg.br/defesas/259M.PDF. Acesso: 25 out. de 2017.

TOLEDO JUNIOR, F. G.; MELO, W.Evolução de processo de aciaria.Coronel Fabriciano, UNILESTE, 2015. Disponível em:

http://www.ebah.com.br/content/ABAAAgwLAAK/evolucao-processo-aciaria. Acesso em: 31 out. de 2017.

WANDEKOKEN, F. G. Desenvolvimento de método para a quantificação de porfirinas de vanadila em frações de petróleo por cromatografia líquida de alta eficiência com injeção em fluxo e espectrometria de massas com plasma indutivamente acoplado. Pontifícia Universidade Católica do Rio de Janeiro - PUC-RIO, 2016. Disponível em: https://www.maxwell.vrac.puc-rio.br/12188/12188 5.PDF. Acesso em: 13 dez. 2017.

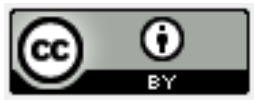

Artigo recebido em: 22/04/2018 e aceito para publicação em: 07/01/2019 DOI: http://dx.doi.org/10.14488/1676-1901.v19i1.3230 